\title{
Trehalose and Sucrose Osmolytes Accumulated by Algae as Potential Raw Material for Bioethanol
}

\author{
Ma. del Pilar Bremauntz ${ }^{1}$, Luis G. Torres-Bustillos ${ }^{1}$, Rosa-Olivia Cañizares-Villanueva ${ }^{2}$, Enrique \\ Duran-Paramo ${ }^{1}$, Luis Fernández-Linares ${ }^{1}$
}

${ }^{1}$ Laboratory of Bioprocesses, Department of Bioprocesses, Unidad Profesional Interdisciplinaria de Biotecnología UPIBI-Instituto Politécnico Nacional, Mexico City, Mexico; ${ }^{2}$ Departamento de Biotecnología y Bioingeniería, Centro de Investigación y de Estudios Avanzados- IPN, Mexico City, Mexico.

Email: pilarbrem@yahoo.com.mx

Received April 29 $9^{\text {th }}$ 2011; revised June 30 ${ }^{\text {th }}, 2011$; accepted July 10 ${ }^{\text {th }}, 2011$.

\begin{abstract}
Currently, obtaining sustainable fuels, such as biodiesel and bioethanol, from cheap and renewable materials is a challenge. In recent years, a new approach being developed consists of producing, sugars from algae by photosynthesis. Sugar accumulation can be increased under osmotic stress (osmoregulation). The aim of this study is to show the production of sugars from algae, isolated from natural sources, and the effect of osmotic stress on fermentable sugars accumulation. Strain isolation, production of sugars from each alga and the effect of osmotic stress on growth and sugar production are described. Twelve algal strains were isolated, showing growths between 0.6 and $1.8 \mathrm{~g}$ of biomass dry weight /L, all with production of intracellular and extracellular sugars. The strain identified as Chlorella sp. showed an increase in sugar production from 23.64 to $421 \mathrm{mg}$ of sugars/g of biomass dry weight after $24 \mathrm{~h}$ of osmotic stress with $0.4 \mathrm{M} \mathrm{NaCl}$. Sucrose and trehalose, both fermentable sugars, were the compatible osmolytes accumulated in response to the osmotic stress. The isolated strains are potential producers of fermentable sugars, using the photosynthetic pathway and osmotic stress.
\end{abstract}

Keywords: Algae, Biofuels, Osmoregulators, Carbohydrates, Bioethanol

\section{Introduction}

Carbon neutral renewable fuels, as bioethanol, are decisive in contributing to the replacement of petroleumderived fuels that contribute to global warming. Production of biodiesel from oil crops and bioethanol from sugarcane and crops in large amounts are not sustainable. An alternative offered by microalgae results from photosynthesis-produced sugars. This production can be increased via osmotic stress as osmolytes accumulation in algae. One mechanism developed by microorganisms as a response to osmotic stress, is the ability to accumulate compatible low-molecular-weight organic solutes such as carbohydrates [1-5].

Three categories of microalgae have been proposed according to their response to salt, a) low stress tolerance to salinity $(0.7 \mathrm{M} \mathrm{NaCl})$, with production of sucrose and trehalose, b) medium tolerance to salinity $(0.7-1.8 \mathrm{M}$ $\mathrm{NaCl}$ ) with production of glucosylglycerol, and c) high tolerance to salinity (more than $2.7 \mathrm{M} \mathrm{NaCl}$ ) with produc- tion of amino compounds such as glycine, betaine, or glutamate [6-9]. The mechanism by which microalgae produce sucrose is through the production of a complex enzyme sucrose-phosphate synthetase/phosphatase (SPS/ SPP) [10].

The aim of this study is to show the effect of osmotic stress in algae fermentable sugars accumulation, as a potential supply source of raw material for alcoholic fermentation.

\section{Material and Methods}

\subsection{Algae Isolation and Culture}

Samples were taken from four different places: the Lake of Texcoco, located in the Metropolitan area of Mexico City (salinity $2000 \mathrm{ppm}, \mathrm{pH} 8$ - 10) [11]; the Lake of Guadalupe, in the State of Mexico (fresh water, $\mathrm{pH} 7.2$, salinity $0.3 \mathrm{ppm}$ ); a lake in Tabasco, southeastern Mexico (pH 7.2 - 7.8, salinity $2000 \mathrm{ppm}$ ); and the river Thames, in Ontario, Canada (pH 6.7, salinity $0.5 \mathrm{ppm}$ ). 
Samples were taken in bottles and, upon arriving to the laboratory, $\mathrm{pH}$ and salinity were determined through conductivity.

Samples were enriched through cultivation in different media according to their salinity, either BG11, BG11 with $25 \% \mathrm{NaCl}$, or Guillard [12]. The culture conditions were, in all experiments: fluorescent light in periods of $12: 12 \mathrm{~h}\left(100 \mathrm{~mol} / \mathrm{m}^{2} \mathrm{~s}\right) ; 25^{\circ} \mathrm{C}$ and aeration $4 \mathrm{vvm}$ (in liquid medium). After two replanting procedures, they were plated onto solid medium (the same culture medium with $10 \%$ agar-agar). After 15 days of incubation, samples of each separate colony were taken from the plate and seeded again in a liquid medium culture at the same above mentioned conditions. Isolated strains were conserved in liquid medium with natural light at room temperature [12]. The strains were identified by optical microscopy using a LEICA-DMLB microscope. Each strain was observed and compared with a taxonomy library [13].

\subsection{Growth Kinetics}

A $250-\mathrm{mL}$ flask with $150 \mathrm{~mL}$ of selected medium was inoculated (10\% inoculum) and cultivated under the previously fixed conditions. Growth was monitored by absorbance (O.D. $600 \mathrm{~nm}$ ) every $24 \mathrm{~h}$ in a colorimeter Genesis $10 \mathrm{UV}$ and by dry weight (dw): culture was filtered through a $0.42 \mathrm{~m}$ pre-weighted filter, dried at $80^{\circ} \mathrm{C}$ for $24 \mathrm{~h}$, and weighted. Culture purity was monitored by optical microscopy.

\subsection{Intra- and Extra-Cellular Sugars Analysis}

The 15-day cell culture was centrifuged at $5000 \mathrm{rpm}$, for $20 \mathrm{~min}$ at $4^{\circ} \mathrm{C}$, in a Beckman J2-MC centrifuge. Liquid phase was separated for total carbohydrate determination. For intracellular sugars, biomass was lyophilized, the dry cells $(0.01-0.05 \mathrm{~g})$ were extracted with $10 \mathrm{~mL}$ of $70 \%$ ethanol and incubated at $65^{\circ} \mathrm{C}$ during $4 \mathrm{~h}$, then they were centrifuged at $10,000 \mathrm{rpm}$ for $15 \mathrm{~min}$ in a Sorvall Biofugeprimo Centrifuge. The supernatants were collected and dried at $40^{\circ} \mathrm{C}$ in an oven. The obtained material was redissolved in $10 \mathrm{~mL}$ of distilled water $[8,14]$. The total carbohydrate content, in both intra- and extra-cellular fractions, was established by the phenol-sulphuric acid method (Dubois Method); and identified by HPLC as established by Müller [8,14], The supernatants were collected and deionised by shaking with mixed-bed resin (Bio-Rad $501 \mathrm{X} 8$ ), the solute was filtered through a microfilter $(22 \mu \mathrm{m})$ prior to injection. A Varian 9002 HPLC with refractive index detector, using a column Phenomenex REYEX organic acid 300X7.8 75985 00H-0138-KO, mobile phase $\mathrm{H}_{2} \mathrm{O} / \mathrm{H}_{2} \mathrm{SO}_{4}$ at a flow rate $0.3 \mathrm{~mL} / \mathrm{min}$, was employed.

\subsection{Effect of Salt Stress on Growth and Osmotic Shock on Sugar Production}

To assess the $\mathrm{NaCl}$ concentration effect on growth, isolated strains were grown in BG11 medium with $0,0.2$, 0.4 , and $0.6 \mathrm{M} \mathrm{NaCl}$ under the same conditions mentioned above. Growth, intra- and extra-celullular, and total carbohydrates were determined during 15 days as indicated before.

The effect of osmotic shock on sugar production was completed by stressing the growth cultures (biomass at $\left.1.5 \mathrm{OD}_{600 \mathrm{~nm}}\right)$ with the addition of $\mathrm{NaCl}$, as concentrated solution, to achieve $0.1,0.2,0.3,0.4,0.5$, and $0.6 \mathrm{M}$; subsequently shocked cultures were incubated during three additional days, growth and intra- and extra-cellular sugars were determined every $24 \mathrm{~h}$, as indicated before.

\section{Results and Discussion}

\subsection{Photosynthetic Microorganisms Isolation and Its Growth}

In the initial stage of this work, twelve different types of photosynthetic microorganisms were isolated and identified, they showed different growths and biomass productions (Table 1).

Table 1. Identification of isolated algae, place of origin, and biomass produced ( $\mathrm{g} \mathrm{dw} / \mathrm{L})$.

\begin{tabular}{lccc}
\hline \multicolumn{1}{c}{ Orden y Género } & Lugar de origen & Máxima biomasa (g/L) & Factor de eficiencia \\
\hline Chlorococcales Chlorella & Lago de Guadalupe & 1.36 & 29.11 \\
Chysospheaceae Chrysosphaera & Lago en Tabasco & 0.32 & 5.44 \\
Chlorococcales Trebouxia & Lago de Guadalupe & 0.6 & 6.22 \\
Chlorococcales Chlorella $(T)$ & Lago en Tabasco & 0.64 & 2.70 \\
Chlorococcales Scenedesmus & Río Tamesi, Canadá & 1.58 & 5.37 \\
Chroococcales Synechocystis & Lago de Texcoco & 1.74 & 1.81 \\
Chroococcales Synechocystis $(T)$ & Lago en Tabasco & 1.18 & 0.83 \\
Nostocales Nodularia & Lago de Texcoco & 2.16 & 1.30 \\
Oscillattoriales Lyngbya & Lago de Texcoco & 2.56 & 1.02 \\
Chroococcales Gloecapsa & Lago en Tabasco & 0.9 & 0.27 \\
Chroococcales Cistococcus & Lago de Texcoco & 1.76 & 0.70 \\
Oscillattoriales Oscillatoria & Río Tamesi Canadá & 1.24 & 2.61 \\
\hline
\end{tabular}

*mg of total sugars/L culture medium 
Among the isolated strains, maximum growth (biomass) occurred in increasing order: Lyngbya, Synechocistis, Cystecocus, Scenedesmus, Chlorella, and Oscillatoria; they showed a final biomass (dw) higher than 1 $\mathrm{g} / \mathrm{L}$ (Figures 1(a) and 1(b)). A second group of strains: Gloecapsa, Chlorella (T), Trebouxia, Nodularia, and Chrysosphaera showed the lowest biomass $\mathrm{dw}(<1)$, i.e., $50 \%$ less than the Lyngbya strain (Figure 1(c)).

In order to establish the sugars-production efficiency for each strain, the yield of total sugars production per gram of dried biomass per liter of algae culture was calculated for each strain. Chlorella sp., Chysospheaceae, Chrysosphaera, Trebouxia, and Scenedesmus were the most efficient producer strains (Table1).

No relationship was found between salinity of the strains place of origin and the natural production (without osmotic stress) of total sugars; for example, strains Chlorella sp. and Trebouxia, which were isolated from the Guadalupe Lake (fresh water), showed different sugar production rates; from these algae, Chlorella produced 4-fold more sugars than Trebouxia (Figure 2).

Given its high efficiency in sugar production, Chlorella $s p$. was selected for the latter osmotic stress assays.

\subsection{Effect of $\mathrm{NaCl}$ Concentration on the Growth and Sugar Production of Chlorella}

Biomass growth was inhibited at 0.4 and $0.6 \mathrm{M}$ of $\mathrm{NaCl}$, and decreased $28 \%$ at $0.2 \mathrm{M}$ (Figure 3). Brown [15] reported a similar phenomenon with Nannochloris bacillaris (Chlorophyceae), whose growth was inhibited $300 \%$ in seawater $(0.8 \mathrm{M})$. Other studies in cyanobateria mention that this type of photosynthetic microorganism presents growth inhibition at $0.4 \mathrm{M} \mathrm{NaCl}$ [16]. Chlorella vulgaris decreases growth $50 \%$ at $0.6 \mathrm{M}, 30 \%$ at 0.4 , and $10 \%$ at $0.2 \mathrm{M}$ [17]. All these species, including Chlorella isolated in this study, undergo a strong growth inhibition even under moderate osmotic stress, which means that they are stenohaline.

\subsection{Osmotic Shock Effect on Sugar Production}

When Chlorella was treated under osmotic shock, increments in the production of sugars were observed (Figure 4). Total sugar production was 18 -fold higher after $24 \mathrm{~h}$ of osmotic shock using $0.4 \mathrm{M} \mathrm{NaCl}(421 \mathrm{mg} / \mathrm{g}$ of biomass $\mathrm{dw}$ ).

Page et al. [8] reported a 15-fold increment of total sugar production under osmotic stress for a strain of Sytonema, after $24 \mathrm{~h}$ in $0.15 \mathrm{M} \mathrm{NaCl}$. When Synechocystis PCC 6714 was grown in BG11, total carbohydrate production increased above 13-fold when the medium was changed to a BG11/100\% seawater [18].

After salt stress, sucrose and trehalose concentrations increased from 1.13 to 1.95 and from 0.012 to 0.019

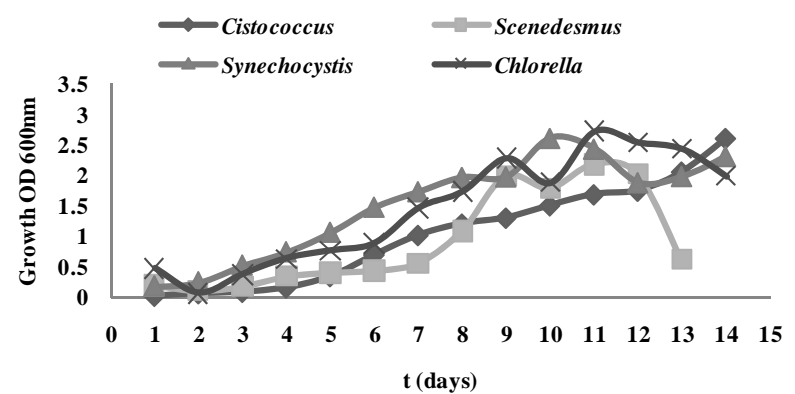

(a)

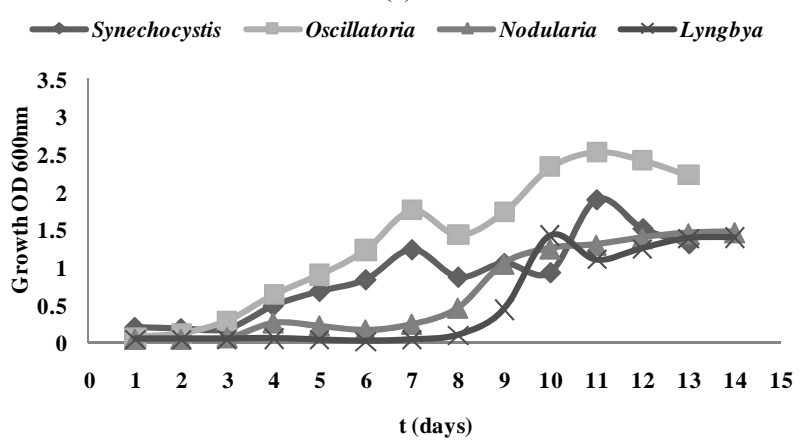

(b)

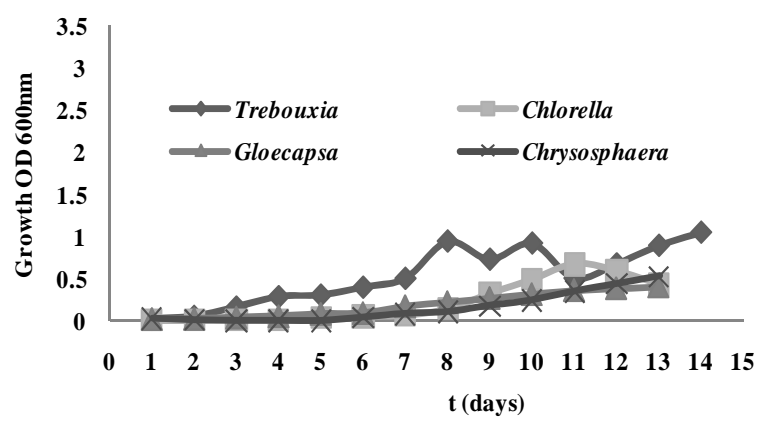

(c)

Figure 1. Kinetic growth of isolated strain cultures in BG11medium.

$\mathrm{mg} / \mathrm{g}$ biomasse dw, respectively, in Chlorella. Under salt stress, Scytonema produced sucrose and trehalose; and trehalose concentration was higher than sucrose [8]; perhaps because trehalose has shown superior protein stabilisation capacity [21]. Chlorella, under osmotic stress, produced proline and sucrose as osmolytes [19-21], aeroterrestrial "Chlorella" trebouxioides SAG2142 and "Chlorella" luteoviridis SAG2196 accumulate the polyols, ribitol and sorbitol [20]. The present study is the first report of trehalose synthesis by Chlorella as osmotic response; nevertheless, in this study sucrose concentration was higher than that of trehalose, being the main osmolyte in Chlorella.

Algae have been used to obtain different products of interest for humans. Microalgae can provide several different types of renewable biofuels. These include meth- 


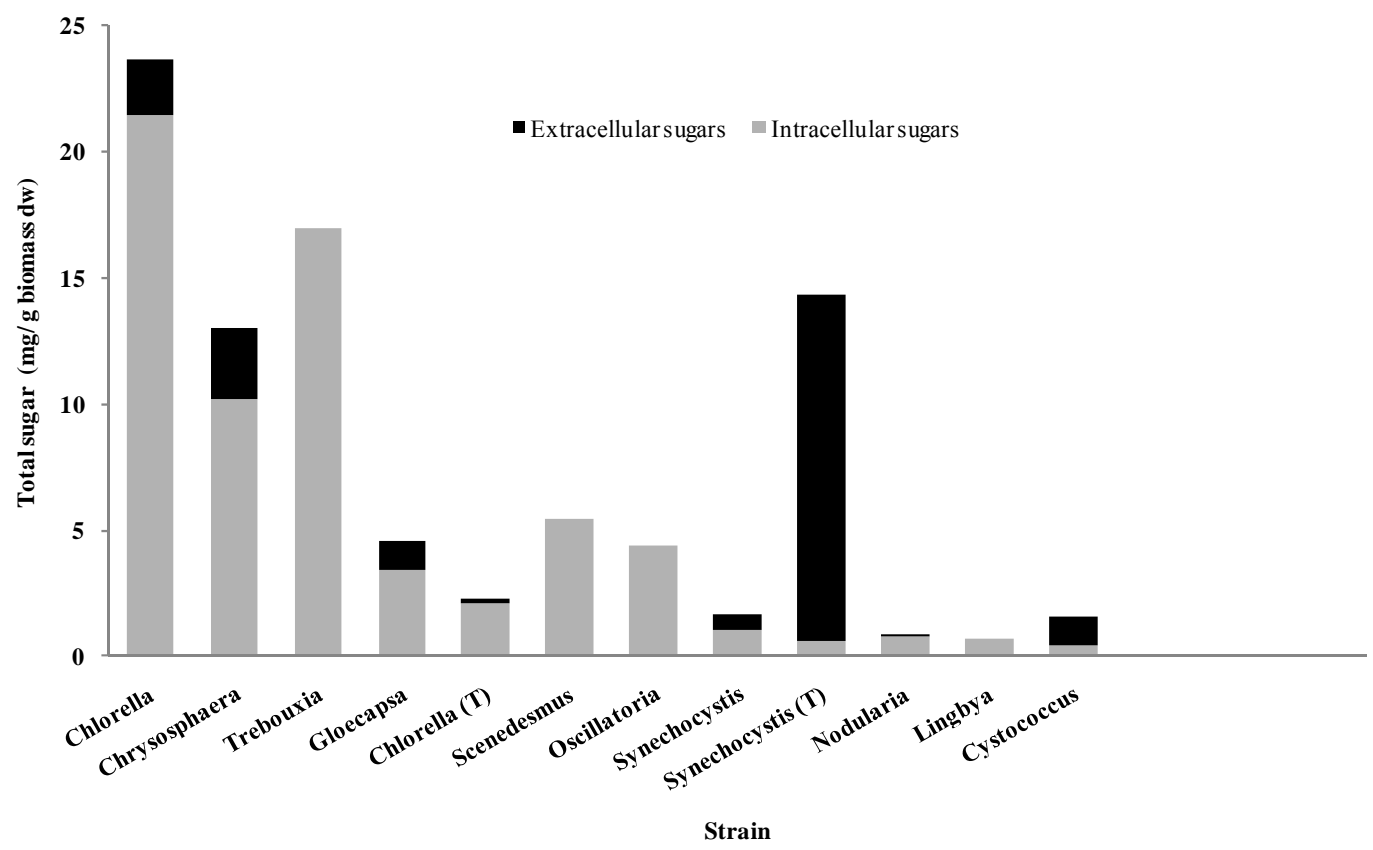

Figure 2. Intra- and extra-cellular sugar production for each isolated strain, grown in BG11 medium without NaCl.

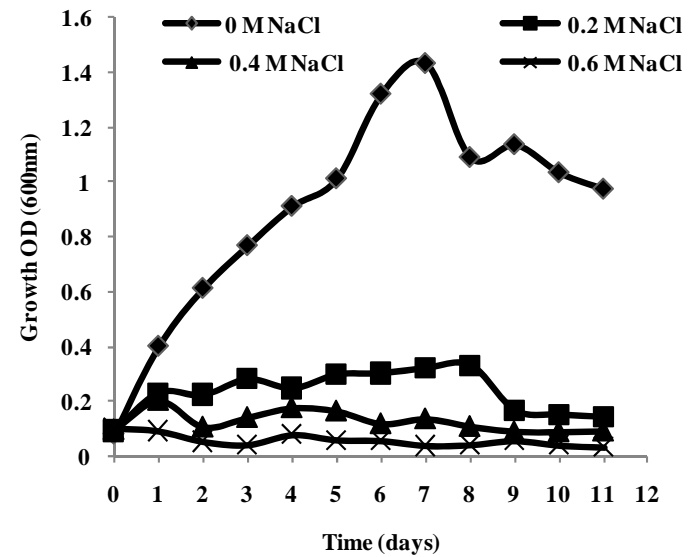

Figure 3. Effect of $\mathrm{NaCl}$ concentration on growth of Chlorella sp.

ane produced by anaerobic digestion of the algal biomass and biohydrogen produced photobiologically, as well as biodiesel derived from microalgal oil [22], bioethanol from sugars and cellulose $[23,24]$, biomass for combustion or hydrogen and methane production.

Aside from using the sugars produced by algae to obtain bioethanol, other celular components as lipids and protein can be used for the synthesis of biodiesel and fodder, respectively; making it more feasible economically to obtain biofuels from algae. When Botryococcus braunii is grown at different $\mathrm{NaCl}$ concentrations, increasing salinity induces a decrease in protein content, but the carbohydrate and lipid contents remain unchanged [25]. Considering the results obtained in the present work re-

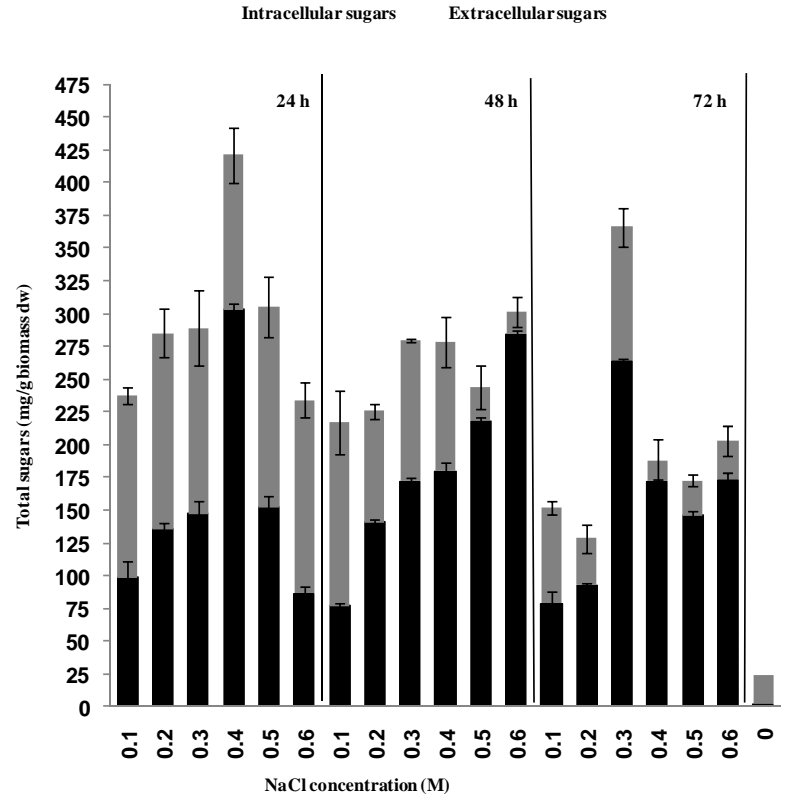

Figure 4. Osmotic stress effect in total sugar production in Chlorella sp grown in BG medium .

garding sugars production by Chlorella, we estimated the annual production of fermentable sugars, considering a hectare of raceways surface of $0.3 \mathrm{~m}$ depth $\left(6000 \mathrm{~m}^{3}\right)$, and a harvested biomass of $20 \%$ of the volume per day, under four different scenarios: $50 \%$ of the maximum biomass production achieved (equivalent to $0.7 \mathrm{~g} / \mathrm{L}$ ) and the maximum biomass (equivalent to $1.36 \mathrm{~g} / \mathrm{L}$ ), both with a sugars yield without osmotic shock (equivalent to 
$0.02 \mathrm{~kg}$ sugar $/ \mathrm{kg}$ biomass $\mathrm{dw}$ ), corresponding to scenarios 1 y 2 , respectively. A $50 \%$ and $100 \%$ of the maximum biomass production achieved with a sugars yield after osmotic shock (equivalent to $0.25 \mathrm{~kg}$ sugar $/ \mathrm{kg} \mathrm{dw}$ ), corresponds to scenarios 3 and 4 , respectively (Table 2). Algal sugar production was compared to the sugar cane productivity in Colombia, where the best yield is 80 and 9.6 ton/ha of sugar cane and sugar, respectively [26-29].

As for production of sugars, in the case of Chlorella in the most conservative condition (scenario 1), the production of sugars is lower (31\%) than sugar cane. Nevertheless, for scenario 2 , it is $13 \%$ higher than that of sugar cane. The two scenarios with osmotic shock, scenarios 3 and 4 are 7 and 14-fold higher than sugar cane, respectively. However, the dilution of sugars in the culture broth is a limiting factor that needs to be considered contrary to sugar cane juice.
As for Chlorella's by-products, lipids, proteins and residual biomass after extraction (cake) were estimated in a very conservative way (based on our results), the percentage of yields were $10 \%, 20 \%$, and $50 \%$, respectively. The values of the by- products estimated with Chlorella are more than one fold higher than those obtained with African oil palm (Elaeis guineensis) (Table 2). Nevertheless, many technical challenges remain in regarding to scaling up and adequate process to make the use of algae feasible for the production of biofuels.

\section{Conclusions}

Twelve strains were isolated from different ecosystems, which produced intra- and extra-cellular carbohydrates. Chlorella sp. showed the highest total sugars production, $29.1 \mathrm{mg}$ of sugars/g dw biomass. When salinity level in culture media was increased, culture growth decreased

Table 2. Comparative scenarios production of sugars, lipids and protein, considering a hectare of raceways surface and $0.3 \mathrm{~m}$ depth, and a harvested biomass of $20 \%$ of the volume per day. Scenario (1) $50 \%$ of the maximal biomass production achieved $(0.7 \mathrm{~g} / \mathrm{L})$; (2) the maximal biomass (1.36 g/L ) both with sugars yield without osmotic shock (0.02 $\mathrm{kg}$ sugar/kg dw), (3) and (4) $50 \%$ and $100 \%$ of the maximum biomass production with sugars yield after osmotic shock (0.25 $\mathrm{kg}$ sugar/kg dw), scenarios 3 and 4, respectively. Sugar cane from Colombia and Oil Palm form Africa.

\begin{tabular}{|c|c|c|c|c|c|}
\hline \multirow{2}{*}{ Feedstock(scenario) } & Biomass & Sugars & Lipids & Protein & Biomass after extraction \\
\hline & \multicolumn{5}{|c|}{ (Ton/Ha/year) } \\
\hline Chlorella (1) & 294 & 5.9 & 29.4 & 59 & 147 \\
\hline Chlorella (2) & 571 & 11 & 57.1 & 114 & 286 \\
\hline Chlorella (3) & 294 & $73.5^{*}$ & 29.4 & 59 & 147 \\
\hline Chlorella (4) & 571 & $142.8^{*}$ & 57.1 & 114 & 286 \\
\hline Sugar cane & 80 & 9.6 & - & $5.2^{(32)}$ & 26 \\
\hline Oil palm & $22^{(29)}$ & $2.6^{(29)}$ & $5.7^{(29)}$ & $3.5^{(30)}$ & $5^{(31)}$ \\
\hline
\end{tabular}

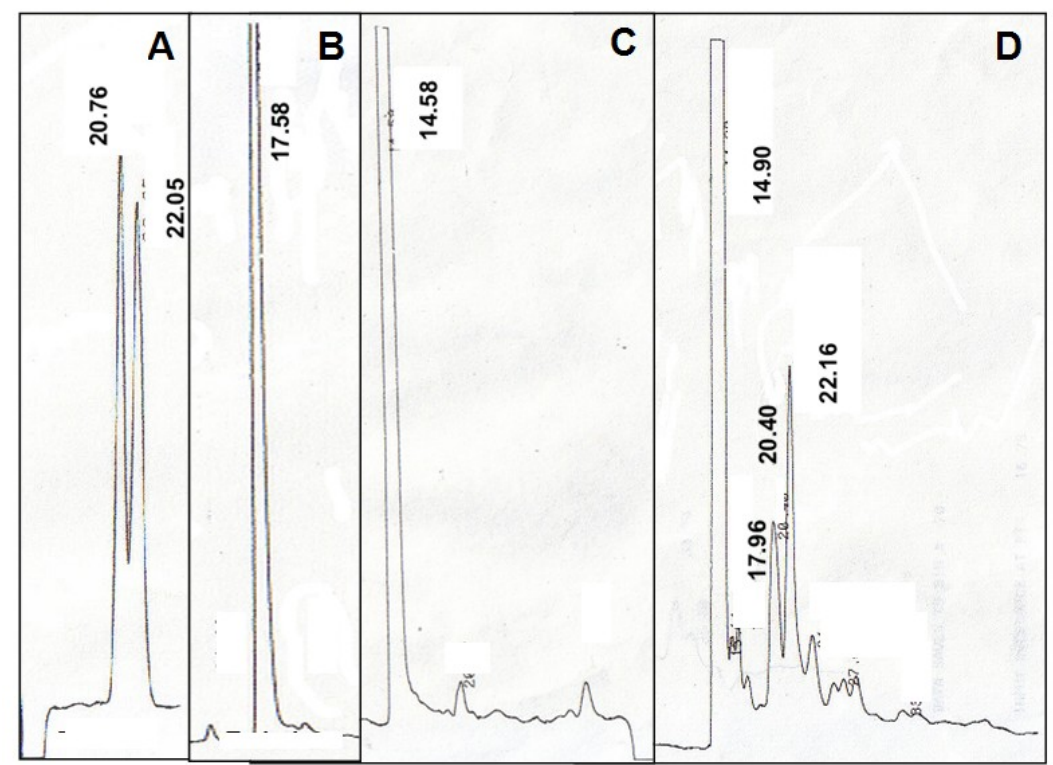

Figure 5. HPLC chromatograms from sacarose standard, A; trehalose standard, B; Chlorella's extract without osmotic stress, C; and Chlorella's extract after 24 h of osmotic stress with $0.4 \mathrm{M} \mathrm{NaCl,} \mathrm{D.}$ 
with increasing $\mathrm{NaCl}$ concentration, and was inhibited at concentrations higher than $0.4 \mathrm{M}$ for all strains.

After the osmotic stress of Chlorella culture, sugar production increased 14-fold in $0.4 \mathrm{M} \mathrm{NaCl}$ after $24 \mathrm{~h}$. The main osmolyte identified was sucrose; however, trehalose was also accumulated (1.93 and $0.019 \mathrm{mg} /$ biomasse $d w$, respectively). These results show the potential use of algae as sugar resource of fermetable sugars and the use of osmotic stress to increase the total sugar production. This work shows also trehalose accumulation as osmolyte by Chlorella.

\section{Acknowledgements}

Funding by Instituto Politecnico Nacional PIFI-20100242.

The microscopy studies and strain identificactions were led by Dr. Ma. Esther Meave from Univesidad Autónoma Metropolitana. Iztapalapa, Mexico.

HPLC analyses were made at the Central Analítica, Depto. de Biotecnología. CINVESTAV-IPN and directed by Elvira Rios, Cirino Rojas, and Gustavo Medina.

\section{REFERENCES}

[1] E. Blumwald, R. Mehlhorn and L. Packer, "Studies of Osmoregulation in Salt Adaptation of Cyanobacteria with ESR Spin-Probe Techniques," Proceedings of National Academy Sciences, Vol. 80, 1983, pp. 2599-2602. doi:10.1073/pnas.80.9.2599

[2] E. Elsheikh and W. Wood, "Rhizobia and Bradyrhizobiz under Salt Stress: Possible Role of Trehalose in Osmoregulation," Letters Applied Microbiology, Vol. 10, 1990, pp. 127-129. doi:10.1111/j.1472-765X.1990.tb00098.x

[3] D. Los and N. Murata, "Membrane Fluidity and Its Role in the Perception of Environmental Signals," Biochimica et Biophysica Acta, Vol. 1666, 2004, pp 142-157. doi:10.1016/j.bbamem.2004.08.002

[4] M. A. Luna-Velasco, F. Esparza-García, R. O. CañizaresVillanueva and R. Rodríguez-Vázquez, "Production and Properties of a Bioemulsifier Synthetsized by Phenanthrene-Degrading Penicillium sp," Process Biochemisty, Vol. 42, 2007, pp. 310-314.

[5] M. C. Santiago-Santos, T. Ponce-Noyola, R. OlveraRamirez, J. Ortega-López and R. O. Cañizares-Villanueva, "Extraction and Purification Phycocyanin from Calothrix sp.," Process Biochemisty, Vol. 39, 2004, pp. 2047-2052.

[6] J. Batterton and C. van Baalen, "Growth Responses of Blue-Green Algae to Sodium Chloride Concentration," Archives Microbiology, Vol. 76, 1971, pp. 151-155. doi:10.1007/BF00411789

[7] F. Joset, R. Jeanjean and M. Hagemann, "Dynamics of the Response of Cyanobacteria to Salt-Stress: Deciphering the Molecular Events," Physiologia Plantarum, Vol. 96, No. 4, 1996, pp. 738-744.

doi:10.1111/j.1399-3054.1996.tb00251.x

[8] M. Page-Sharp, C. Behm and G. Smith, "Involvement ofCompatible Solutes Trehalose and Sucrose in the Re- sponse to SALT Stress of Cyanobaterial Scytonema Species Isolated from Desert Solils," Biochimica et Biophysica Acta, Vol. 1472, 1999, pp. 519-528.

[9] G. Stacey, C. Van Baalen and F. Tabita, "Isolation and Characterization of a Marine Anabaena sp. Capable of Rapid Growth on Molecular Nitrogen," Archives of Microbiology, Vol. 144, 1977, pp. 197-201. doi:10.1007/BF00446862

[10] A. Porchia and G. Salerno, "Sucrose Biosynthesis in a Prokaryotic Organism: Presence of Two Sucrose-Phosphate Synthases in Anabaena with Remarkable Differences Compared with the Plant Enzymes," Proceedings of National Academy Sciences, Vol. 93, 1996, pp. 1360013604. doi:10.1073/pnas.93.24.13600

[11] National Water Commission Report, "Informe SU-6-C03 -3-390," 1996. http://www.cna.gob.mx/OCAVM

[12] R. Rippka, J. Deruelles, J. Waterbury, M. Herdman and R. Stanier, "Generic Assignments, Strain Histories and Properties of Pure Cultures of Cyanobacteria," Journal of General Microbiology, Vol. 111, 1979, pp. 1-61.

[13] P. Bourrely, "Les Algues d'eau douce," Editions N. Boubeé \& Cie., Paris, 1966.

[14] J. Müller, C. Staehelin, R. Mellor, T. Boller and A. Wiemken, "Trehalose and Trehalase in Root Nodules from Various Legumes," Physiologia Plantarum, Vol. 90, No. 1, 1994, pp. 86-92.

[15] L. Brown, "Photosynthetic and Growth Responses to Salinity in a Marine Isolated Nannochloris bacillaris (Chlorophyceae)," Journal of Phicology, Vol. 18, No. 4, 1982, pp. 483-488.

[16] R. Abed, K. Kohl and D. Beer, "Effect of Salinity Changes on the Bacterial Diversity Photosynthesis and Oxygen Consumption of Cyanobacterial Mats from an Intertidal of Arabian Gulf," Environmental Microbiology, Vol. 9, No. 6, 2007, pp. 1384-1392. doi:10.1111/j.1462-2920.2007.01254.x

[17] L. Gustavs, A. Eggert, D. Michalik and U. Karten, "Physiological and Biochemical Responses of Green Microalgae from Different Habitats to Osmotic and Matric Stress," Protoplasma, Vol. 243, No. 1-4, 2010, pp. 3-14.

[18] C. Colaco, C. Smith, S. Sen, D. Roser, Y. Newman, S. Ring, (Eds.), "Formulation and Delivery of Proteins and Peptides. IV Series," American Chemical Society, Washington, D.C., 1993, pp. 220-240.

[19] A. Oren," Diversity of Organic Osmotic Compounds and Osmotic Adaptation in Cyanobacteria and Algae," In: Seckback Ed., Algae and Cyanobacteria in Extreme Environment, Springer, Berlin, 2007, pp. 639-655.

[20] A. Ben Amotz and M. Avron, "Accumulation of Metabolities by Halotolerant Algae and Its Industrial Potencial," Annual Review Microbiology, Vol. 37, 1983, pp. 95-119. doi:10.1146/annurev.mi.37.100183.000523

[21] A. Ben-Amotz and T. Grunwald, "Osmoregulation in the Halotolerant Algae Asteromonas gracilis," Plant Physiology, Vol. 67, 1981, pp. 613-616.

[22] Y. Chisti, "Biodiesel from Microalgae," Biotechnology Advances, Vol. 25, No. 3, 2007, pp. 294-306. 
doi:10.1016/i.biotechadv.2007.02.001

[23] J. Zaldivar, J. Nielsen and L. Olsson, "Fuel Ethanol from Lignocelluloses: A Challenge for Methabolic Engineering and Process Integration," Applied Microbiology and Biotechnology, Vol. 56, No. 1-2, 2001, pp. 17-34. doi:10.1007/s002530100624

[24] C. Posten and G. Schaub, "Microalgae and Terrestrial Biomass as Source for Fuels-A Process View," Journal of Biotechology, Vol. 142, No. 1, 2009, pp. 142: 64-69.

[25] R. Vazquez-Duhalt and B. Arredondo, "Haloadaptation of a Green Alga Botryococcus braunii (Race A)," Phytochemistry, Vol. 30, No. 9, 1991, pp. 2919-2915.

[26] E. Visser, D. Filhi, M. Martins and B. Steward, "Bioethanol Production Potential from Brazilian Biodiesel CoProducts," Biomass and Bioenergy, Vol. 35, 2011, pp. 489494. doi:10.1016/j.biombioe.2010.09.009
[27] L. P. F. Carvalho, A. R. J. Cabrita, R. J. Dewhurst, T. E. J. Vicente, Z. M. C. Lopes and A. J. M. Fonseca, "Evaluation of Palm Kernel Meal and Corn Distillers Grains in Corn Silage-Based Diets for Lactating Dairy Cows," Journal of Dairy Science, Vol. 89, No. 7, 2006, pp. 27052715.

[28] S. Yusoff, "Renewable Energy from Palm Oil-Innovation on Effective Utilization of Waste," Journal of Cleaner Production, Vol. 14, No.1, 2006, pp. 87-93. doi:10.1016/j.jclepro.2004.07.005

[29] A. Córdova-Izquierdo, J. A. Lara Torres, R. Amaro Gutiérrez, S. D. Peña Betancourt and V. M. Xolalpa Campos, "Composition of Milk from Holstein Cows Supplemented with Sugar Cane Enriched Comprehensive Paperback Saccharina," Revista Veterinria, Vol. 1, No. 1, 2010, pp. 66-68. 